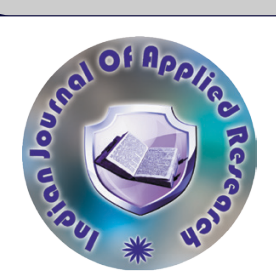

Radiodiagnosis

\title{
POSTOPERATIVE EVALUATION AND EXPECTED COMPLICATIONS OF PERORAL ENDOSCOPIC MYOTOMY FOR ACHALASIA CARDIA - USING LOW DOSE MULTI DETECTOR COMPUTED TOMOGRAPHY WITH ORAL CONTRAST
}

\begin{tabular}{l}
\hline $\begin{array}{l}\text { Amarnath } \\
\text { Chellathurai }\end{array}$ \\
\hline Chezhian \\
Jayabalan * \\
\hline Nellaiappan \\
Chelliah \\
\hline Sathyan \\
Gnanasigamani \\
\hline
\end{tabular}

Karthik Ganesan
Professor and Head of the Department, Department of Radio-Diagnosis, Government Stanley Medical College, Chennai-600001

Associate Professor, Department of Radio-Diagnosis, Government Stanley Medical College, Chennai-600001*Corresponding Authors

\section{Department of Radio-Diagnosis, Government Stanley Medical College, Chennai-} 600001

Professor, Department of Radio-Diagnosis, Government Stanley Medical College, Chennai-600001

Junior Resident, Department of Radio-Diagnosis, Government Stanley Medical College, Chennai-600001

\section{ABSTRACT}

Background: Per Oral Endoscopic Myotomy (POEM) is a promising new endoscopic method for the treatment of achalasia cardia. Available current data from various meta-analyses shows short term success with minimal adverse events. Here we aim to study the post procedural adverse events of POEM procedure using postoperative low dose multi detector CT chest with oral contrast.Methods: A retrospective study involving 43 patients who underwent POEM procedure for achalasia, were evaluated on postoperative day 1 chest CT study with oral contrast. Results: 30 out of the 43 patients (69.8\%) had pleural effusion. 29 cases $(67.5 \%)$ had small pleural effusion and one case $(2.3 \%)$ had moderate effusion. None had large pleural effusion. Small left pneumothorax was noted in 1 patient $(2.3 \%)$, which was however not severe enough to produce respiratory complaints or necessitated intercostal drain tube placement. One patient had 2 mucosal defects in the lower oesophagus with submucosal and extra luminal contrast leak, causing mediastinal collection and communication with left pleural cavity resulting in empyema which required intercostal drainage. Minimal intramural contrast leak with no extraluminal leak or mediastinal collection was present in 5 patients $(11.6 \%)$, and all 5 were managed with second clipping. Bilteral lower lobe consolidation was noted in 1 case $(2.3 \%)$, suggesting the possibility of aspiration. The patient had an uneventful postoperative course obviating the necessity of any further specific management. Minimal basal atelectasis were seen in 8 patients (18.4\%), few linear opacities suggestive of pneumonitis were seen in 2 patients $(4.6 \%)$, pneumomediastinum was found in 11 patients $(25.5 \%)$, pneumoperitoneum in 24 patients $(60.5 \%)$ and subcutaneous emphysema in 12 patients $(28 \%)$. None of them were severe enough to produce clinical effects and none required any specific intervention. Conclusion: POEM procedure being preferred now in the management of achalasia cardia, it is of pertinent importance for the radiologists to be aware of the adverse events that could occur post procedure, and to differentiate the expected postoperative findings from the more sinister complications like perforation, which causes significant morbidity and mortality.

KEYWORDS : Dysphagia; Achalasia; per oral endoscopic myotomy (POEM).

\section{INTRODUCTION}

Achalasia is an oesophageal motility disorder characterized by a combination of impaired lower oesophageal sphincter (LES) opening and absent peristalsis in the oesophagus in response to deglutition. The most widely used treatment options include endoscopic balloon dilation and laparoscopic or open Heller myotomy [1,2]. Peroral endoscopic myotomy (POEM) was recently introduced novel method which is less invasive as it is carried out through orifice naturalis. This procedure has shown promising short-term results reported by few smaller studies, though it is too early to predict long term results for such a recently introduced procedure $[3,4]$. The procedure includes four steps, the incision of lower oesophageal mucosa, creating a submucosal tunnel, myotomy and closure of the mucosal incision. This procedure is associated with few post procedure adverse events such as pneumothorax, pneumomediastinum, pneumoperitoneum, pleural effusion, subcutaneous emphysema, and submucosal and extraluminal mucosal leaks. These adverse events can be identified by crosssectional imaging, and shows the necessity of post- POEM CT study $[5,6,7]$. Our study aims to study the post procedural adverse events of POEM procedure, using postoperative low dose multi detector CT chest with oral contrast.

\section{MATERIALS AND METHODS}

It is a cross sectional study at a tertiary care centre involving 43 patients who underwent per oral endoscopic myotomy (POEM) procedure for achalasia cardia, and evaluated on postoperative day 1 by low dose chest CT scan with oral contrast. The period of study was for 5 years from January 2015 to December 2019. Approval from institutional ethical committee was obtained. The study included 20 female and 23 male patients and their mean age was 40.4 years.

\section{INCLUSION CRITERIA:}

Patients who underwent POEM procedure for primary achalasia cardia were included. The diagnosis of achalasia was done based on the clinical symptoms and barium oesophagogram demonstrating typical bird's beak appearance of the lower oesophageal sphincter and delay in the emptying time of the barium.

\section{EXCLUSION CRITERIA:}

1. Patients for whom the diagnosis of achalasia could not be confirmed by manometry.

2. Patients with oesophageal or upper gastric tumours.

Details regarding patient demographics, clinical course, during and after the procedure were retrospectively analysed using data from the medical records department. Non contrast and post-contrast chest CT with oral contrast were taken on postoperative day 1 . Images were taken in the axial sections and reformatted in sagittal and coronal planes. Continuous serial axial sections were taken, of thickness $5 \mathrm{~mm}$, with interval of $5 \mathrm{~mm}$ and large FOV in cranio-caudal direction from the level of suprasternal notch to the upper abdomen, before and after administration of oral contrast $(10-20 \mathrm{ml}$ water soluble iodinated contrast $350 \mathrm{mg}$ iodine $/ \mathrm{ml}$ in $500-1000 \mathrm{ml}$ distilled water).

The CT chest was evaluated to look for the following findings. The number and position of the oesophageal clips and to rule out any clip dislocation. The presence of pneumomediastinum, pneumothorax, subcutaneous emphysema, pneumoperitoneum and retroperitoneal free air were noted. The post procedural oesophageal dilatation and narrowing at GE junction, if any, were noted. Free flow of contrast into the stomach ensured. Most importantly the presence of submucosal or extraluminal oral contrast extravasation or mediastinal collection/ hematoma to be ruled out, as they may indicate oesophageal mucosal/ 
wall perforation, as they are associated with high morbidity. Bilateral lung fields and pleura were also assessed.

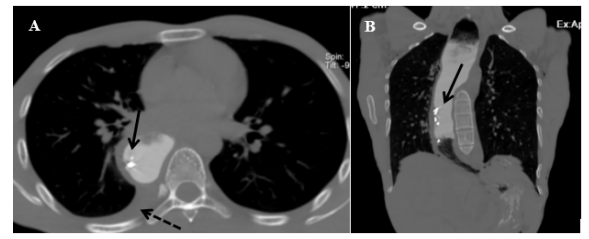

Figure 1(A,B): Low dose MDCT chest with oral contrast shows post surgical clips (bold arrows) in the right lateral wall and posterior wall of mid-lower thoracic oesophagus. There is a moderate dilatation of oesophagus. No oral contrast extravasation. No evidence of mediastinal loculations. Contrast is freely going in to stomach. Minimal right pleural effusion (dotted arrow).

Pneumothorax was reported based on manual volume estimation using CT by the radiologists. Pneumothorax was quantified as small if volume was less than $30 \mathrm{ml}$ and as large if volume was $30 \mathrm{ml}$ or larger [8]. The need for intervention was defined as a pneumothorax greater than $30 \%$ of the volume of hemithorax, developed in patients after or during the procedure, as seen on CT or bedside radiography. Such cases were to be managed with central venous catheter or intercostal drainage tube inserted at the third or fourth intercostal for drainage. In addition, clinical symptoms such as apparent dyspnea were also considered.

The amount of pleural effusion on CT imaging is classified as small, moderate, or large according to the anteroposterior (AP) quartile. First AP quartile effusions are small, second AP quartile effusions are moderate, and third or fourth AP quartile effusions are large [9].

Small effusions in this study, measuring $<25 \%$ of the hemithorax, needed no drainage, unless, if needed clinically. In such cases they have to be managed with ultrasonography guided thoracocentesis. Moderate effusions, measuring $25 \%$ to $50 \%$ of the hemithorax, are generally managed with ultrasonography guided thoracentesis. In large effusions, measuring $>50 \%$ of the hemithorax, thoracocentesis can be performed even without ultrasonography guidance. Symptomatic patients or patients with persistently high temperature underwent an ultrasonography guided drainage.

The selective circular muscle myotomy is suggested to prevent the endoscope entering the pleural space which is however technically difficult because the longitudinal muscle fibers of the esophagus are very thin, and therefore sometimes splitting of these fibers occur during POEM. Also electrocauterisation, $\mathrm{CO} 2$ insufflation can result in splitting of the longitudinal muscle layer and adventitia. This causes communication with the mediastinum or peritoneum, resulting in pneumomediastinum and pneumoperitoneum respectively, and subsequently into the subcutaneous plane of neck and thorax resulting in subcutaneous emphysema. Patients were usually discharged on the third postoperative day if there were no symptoms or fever. The clinical endpoint of this study was the date of hospital discharge.

\section{RESULTS}

All the data were shown in tables and figures are analysed in the below sections. Statistical correlation was based on proportion and percentage. Statistical analysis was performed with SPSS 16.0 software (SPSS, Inc, Chicago, Ill). Descriptive statistics were used to depict the patients' characteristics (mean and standard deviation as well as median and range). Univariate analysis of clinical characteristics and operation factors was performed by using the Chi square test. $\mathrm{P}$ values $<0.05$ were considered statistically significant. 43 patients were evaluated, 20 females and 23 males, and the mean age was found to be 40.4 years (standard deviation 15.6 years).

30 out of the 43 patients $(69.8 \%)$ had pleural effusion. 29 cases $(67.5 \%)$ had small pleural effusion, effusion within first AP quartile. One case $(2.3 \%)$ had moderate effusion within second AP quartile, and was managed with ultrasound guided pleural tapping. None had large pleural effusion. 20 cases had(46.5\%) had bilateral pleural effusion, of which 8 cases had more effusion on the right side and 1 case had predominant left pleural effusion. 11 cases had more or less same amount of effusion on both sides. Isolated right sided pleural effusion was seen in 8 patients $(18.6 \%)$ and isolated left sided pleural effusion was present in 2 patients $(4.6 \%)$.
Small pneumothorax was noted in 1 patient $(2.3 \%)$, on the left pleural cavity. Pneumothorax volume was $8 \%$ of the left hemithorax. However, it was not severe enough to produce respiratory complaints or necessitated intercostal drain tube placement.

One patient, whose postoperative day $1 \mathrm{CT}$ scan was normal except for the wall thickening in the lower thoracic oesophagus and OG junction, with no evidence of contrast leak, on repeat CT on the postoperative day 15 for vague epigastric pain and fever, showed 2 mucosal defects in the lower oesophagus, measuring about $11 \times 25 \mathrm{~mm}$ along the lower aspect of the clips and the other measuring about $9 \times 18 \mathrm{~mm}$ in the posterior mucosa just below the former. Contrast leak into submucosal space was seen with extra thoracic tracking of the contrast in to the lower mediastinum on left side. Mediastinal collection measuring about $4.5 \times 2 \times 2.6 \mathrm{~cm}$ (Volume - 12cc) was seen communicating with left pleural cavity. Moderate left pleural effusion with loculation was noted along the left posteromedial paravertebral region (volume around $250 \mathrm{cc})$ and upper posterior chest wall $(\sim 160 \mathrm{cc})$, suggestive of empyema. Contrast was seen freely entering into the stomach and there was no evidence of OG junction wall thickening. Intercostal drainage tube was placed for the empyema and the patient put was under antibiotic cover and follow up. Contrast taken 10 days later on postoperative day 25 showed decrease in the size of the mediastinal collection (Volume $-12 \mathrm{cc}$ ) and near complete resolution of the empyema (Volume - 20cc) with ICD in situ. Postoperative day 42 CT showed nil contrast leak. There was complete resolution of the mediastinal collection. Mild wall thickening of the lower thoracic oesophagus and GE junction was present and free flow of contrast into the stomach was seen.

Minimal intramural contrast leak with no extraluminal leak was noted in the oesophagus just adjacent to the metallic clips in 5 patients $(11.6 \%)$. None of these 5 cases had pneumomediastinum or mediastinal collection. Free flow of contrast into the stomach was noted. All 5 cases were managed with second clipping, and repeat CT taken after 4 days showed significant decrease in the intramural contrast leak.
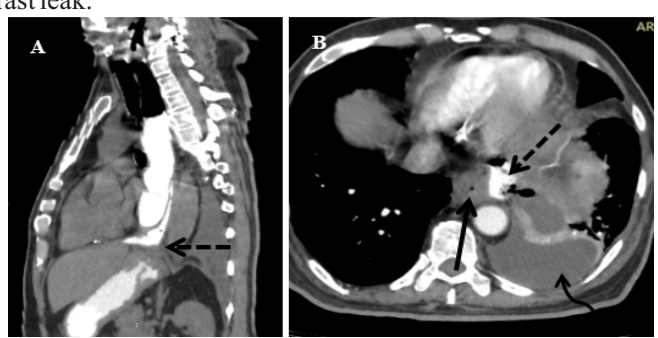

Fig 2 (A,B): CT thorax with oral contrast showing extraluminal contrast leak with mediastinal collection (dotted arrow), which is extending towards the left pleural cavity. Left empyema (curved arrow) seen in close proximity to the mediastinal collection. Wall thickening of the lower thoracic oesophagus (arrow) seen.

Consolidation was noted in 1 case, a 33 year old male had bilateral lower lobe consolidation with no constitutional signs and symptoms of infection. The patient had nil significant adverse respiratory history preoperatively, thus suggesting the possibility of aspiration. The patient had an uneventful postoperative course obviating the necessity of any further specific management. Minimal basal atelectasis were seen in 8 patients $(18.4 \%)$, few linear opacities suggestive of pneumonitis were seen in 2 patients $(4.6 \%)$ and were of little clinical significance and did not necessitate specific management.

Pneumomediastinum were found in 11 patients $(25.6 \%)$, pneumoperitoneum in 26 patients $(60.5 \%)$, retroperitoneal free air in 11 patients $(25.6 \%)$ and subcutaneous emphysema in 12 patients $(28 \%)$. These findings were very minimal on CT, and did not cause any clinical sign or symptom on follow up. No specific intervention was required for them.

\begin{tabular}{|l|l|l|}
\hline Adverse events & No. of cases & Percentage (\%) \\
\hline Pleural effusion & $\mathbf{3 0}$ & $\mathbf{6 9 . 8}$ \\
Small effusion & 29 & 67.5 \\
Moderate effusion & 1 & 2.3 \\
Large effusion & 0 & 0 \\
Bilateral pleural effusion & 20 & 46.5 \\
Isolated right sided effusion & 8 & 18.6 \\
Isolated left sided effusion & 2 & 4.6 \\
\hline
\end{tabular}


Volume - 10 | Issue - 9 | September - 2020 | PRINT ISSN No. 2249 - 555X | DOI : 10.36106/ijar

\begin{tabular}{|l|l|l|}
\hline \hline Pneumothorax & $\mathbf{1}$ & $\mathbf{2 . 3}$ \\
Small pneumothorax & 1 & 2.3 \\
Large pneumothorax & 0 & \\
\hline Pneumomediastinum & 11 & 25.5 \\
\hline Pneumoperitoneum & 26 & 60.5 \\
\hline Retroperitoneal air & 11 & 25.5 \\
\hline Subcutaneous emphysema & 12 & 28.0 \\
\hline Pneumonitis & 3 & 6.9 \\
Consolidation & 1 & 2.3 \\
\hline Minimal basal atelectasis & 8 & 18.4 \\
\hline Intramural leak & $\mathbf{5}$ & $\mathbf{1 1 . 6}$ \\
\hline Extra luminal leak with & $\mathbf{1}$ & $\mathbf{2 . 3}$ \\
mediastinal collection & & \\
\hline
\end{tabular}

\begin{tabular}{|c|c|c|c|}
\hline & $\begin{array}{c}\text { Pleural Effusion } \\
\text { present }\end{array}$ & \begin{tabular}{|c|}
$\begin{array}{c}\text { Pleural Effusion } \\
\text { absent }\end{array}$ \\
\end{tabular} & $\begin{array}{c}\text { Marginal } \\
\text { Row Totals }\end{array}$ \\
\hline Male & $18(16.05) \quad[0.24$ & \begin{tabular}{|lll}
5 & $(6.95)$ & {$[0.55]$}
\end{tabular} & 23 \\
\hline Female & $\begin{array}{lll}12 & (13.95) & {[0.27}\end{array}$ & $\begin{array}{lll}8 & (6.05) & {[0.63]}\end{array}$ & 20 \\
\hline $\begin{array}{c}\text { Marginal } \\
\text { Column Totals }\end{array}$ & 30 & 13 & $\begin{array}{c}43 \text { (Grand } \\
\text { total) }\end{array}$ \\
\hline
\end{tabular}

Chi-square statistic is 1.691 . The p-value is 0.193

\begin{tabular}{|c|c|c|c|c|c|c|c|}
\hline \multicolumn{8}{|c|}{ Crosstab } \\
\hline & & & \multicolumn{4}{|c|}{ PLEURAL EFFUSION } & \multirow[b]{2}{*}{ Total } \\
\hline & & & \begin{tabular}{|l|} 
Absen \\
$\mathbf{t}$
\end{tabular} & Small & $\begin{array}{l}\text { Moderat } \\
\mathrm{e}\end{array}$ & $\begin{array}{l}\text { Larg } \\
\mathrm{e}\end{array}$ & \\
\hline \multirow{10}{*}{$\begin{array}{l}\text { AGE } \\
\text { GROU } \\
\text { P }\end{array}$} & \multirow{2}{*}{$<20$} & Count & 1 & 1 & 0 & 0 & 2 \\
\hline & & Percentage & $2.3 \%$ & $2.3 \%$ & $0 \%$ & $0 \%$ & $4.6 \%$ \\
\hline & \multirow{2}{*}{$21-30$} & Count & 6 & 7 & 0 & 0 & 13 \\
\hline & & Percentage & $14 \%$ & $16.3 \%$ & $0 \%$ & $0 \%$ & \begin{tabular}{l|}
30.2 \\
$\%$
\end{tabular} \\
\hline & \multirow{2}{*}{$31-40$} & Count & 0 & 8 & 0 & 0 & 8 \\
\hline & & Percentage & $0 \%$ & $18.5 \%$ & $0 \%$ & $0 \%$ & $\begin{array}{l}18.5 \\
\% \\
\end{array}$ \\
\hline & \multirow{2}{*}{$41-50$} & Count & 3 & 7 & 0 & 0 & 10 \\
\hline & & Percentage & $7 \%$ & $16.3 \%$ & $0 \%$ & $0 \%$ & $\begin{array}{l}23.3 \\
\% \\
\end{array}$ \\
\hline & \multirow{2}{*}{$>50$} & Count & 3 & 6 & 1 & 0 & 10 \\
\hline & & Percentage & $7 \%$ & $14 \%$ & $2.3 \%$ & $0 \%$ & \begin{tabular}{l|}
23.3 \\
$\%$ \\
\end{tabular} \\
\hline \multirow{2}{*}{\multicolumn{2}{|c|}{ Total }} & Count & 13 & 29 & 1 & $\mathbf{0}$ & 43 \\
\hline & & Percentage & $30.3 \%$ & $67.4 \%$ & $2.3 \%$ & $0 \%$ & $\begin{array}{l}100.0 \\
\%\end{array}$ \\
\hline
\end{tabular}

Chi-square statistic is 3.399. The p-value is 0.906

\begin{tabular}{|c|c|c|c|}
\hline \multicolumn{4}{|l|}{ Crosstab } \\
\hline & & & PNEUMOMEDIASTINUM \\
\hline \multirow{10}{*}{$\begin{array}{l}\text { AGE } \\
\text { GROUP }\end{array}$} & \multirow[t]{2}{*}{$<20$} & Count & 0 \\
\hline & & Percentage & $0 \%$ \\
\hline & \multirow[t]{2}{*}{$21-30$} & Count & 4 \\
\hline & & Percentage & $9.3 \%$ \\
\hline & \multirow[t]{2}{*}{$31-40$} & Count & 4 \\
\hline & & Percentage & $9.3 \%$ \\
\hline & \multirow[t]{2}{*}{$41-50$} & Count & 1 \\
\hline & & Percentage & $2.3 \%$ \\
\hline & \multirow[t]{2}{*}{$>50$} & Count & 2 \\
\hline & & Percentage & $4.6 \%$ \\
\hline \multirow{2}{*}{\multicolumn{2}{|c|}{ Total }} & Count & 11 \\
\hline & & Percentage & $25.5 \%$ \\
\hline
\end{tabular}

Chi-square statistic is 4.384 . The p-value is 0.356

\begin{tabular}{|c|c|c|c|}
\hline \multicolumn{4}{|c|}{ Crosstab } \\
\hline & & & PNEUMOPERITONEUM \\
\hline \multirow{9}{*}{$\begin{array}{c}\text { AGE } \\
\text { GROUP }\end{array}$} & \multirow[t]{2}{*}{$<20$} & Count & 0 \\
\hline & & Percentage & $0 \%$ \\
\hline & \multirow[t]{2}{*}{$21-30$} & Count & 8 \\
\hline & & Percentage & $18.6 \%$ \\
\hline & \multirow[t]{2}{*}{$31-40$} & Count & 6 \\
\hline & & Percentage & $14 \%$ \\
\hline & \multirow[t]{2}{*}{$41-50$} & Count & 7 \\
\hline & & Percentage & $16.3 \%$ \\
\hline & $>50$ & Count & 5 \\
\hline
\end{tabular}

\begin{tabular}{|c|c|c|}
\hline & Percentage & $\mathbf{1 1 . 6 \%}$ \\
\hline \multirow{2}{*}{ Total } & Count & $\mathbf{2 6}$ \\
\cline { 2 - 3 } & Percentage & $\mathbf{6 0 . 5 \%}$ \\
\hline
\end{tabular}

Chi-square statistic is 3.736 . The p-value is 0.443

\begin{tabular}{|c|c|c|c|}
\hline \multicolumn{4}{|l|}{ Crosstab } \\
\hline & & & RETROPERITONEAL AIR \\
\hline \multirow{10}{*}{$\begin{array}{l}\text { AGE } \\
\text { GROUP }\end{array}$} & \multirow[t]{2}{*}{$<20$} & Count & 1 \\
\hline & & Percentage & $2.3 \%$ \\
\hline & \multirow[t]{2}{*}{$21-30$} & Count & 5 \\
\hline & & Percentage & $11.5 \%$ \\
\hline & \multirow[t]{2}{*}{$31-40$} & Count & 4 \\
\hline & & Percentage & $9.2 \%$ \\
\hline & \multirow[t]{2}{*}{$41-50$} & Count & 1 \\
\hline & & Percentage & $2.3 \%$ \\
\hline & \multirow[t]{2}{*}{$>50$} & Count & 0 \\
\hline & & Percentage & $0 \%$ \\
\hline \multirow{2}{*}{\multicolumn{2}{|c|}{ Total }} & Count & 11 \\
\hline & & Percentage & $25.5 \%$ \\
\hline
\end{tabular}

Chi-square statistic is 7.798. The p-value is 0.099

\begin{tabular}{|c|c|c|c|}
\hline \multicolumn{4}{|l|}{ Crosstab } \\
\hline & & & SUBCUTANEOUS EMPHYSEMA \\
\hline \multirow{10}{*}{$\begin{array}{l}\text { AGE } \\
\text { GROUP }\end{array}$} & \multirow[t]{2}{*}{$<20$} & Count & 0 \\
\hline & & Percentage & $0 \%$ \\
\hline & \multirow[t]{2}{*}{$21-30$} & Count & 5 \\
\hline & & Percentage & $11.6 \%$ \\
\hline & \multirow[t]{2}{*}{$31-40$} & Count & 2 \\
\hline & & Percentage & $4.6 \%$ \\
\hline & \multirow[t]{2}{*}{$41-50$} & Count & 2 \\
\hline & & Percentage & $4.6 \%$ \\
\hline & \multirow[t]{2}{*}{$>50$} & Count & 3 \\
\hline & & Percentage & $7.1 \%$ \\
\hline \multirow{2}{*}{\multicolumn{2}{|c|}{ Total }} & Count & 12 \\
\hline & & Percentage & $28 \%$ \\
\hline
\end{tabular}

Chi-square statistic is 3.361 . The p-value is 0.499

\begin{tabular}{|c|c|c|c|c|}
\hline \multicolumn{5}{|l|}{ Crosstab } \\
\hline & & & PNEUMONITIS & $\begin{array}{l}\text { BASAL } \\
\text { ATELECTASIS }\end{array}$ \\
\hline \multirow{10}{*}{$\begin{array}{l}\text { AGE } \\
\text { GROUP }\end{array}$} & \multirow[t]{2}{*}{$<20$} & Count & 1 & 0 \\
\hline & & Percentage & $2.3 \%$ & $0 \%$ \\
\hline & \multirow[t]{2}{*}{$21-30$} & Count & 1 & 1 \\
\hline & & Percentage & $2.3 \%$ & $2.3 \%$ \\
\hline & \multirow[t]{2}{*}{$31-40$} & Count & 1 & 1 \\
\hline & & Percentage & $2.3 \%$ & $2.3 \%$ \\
\hline & \multirow[t]{2}{*}{$41-50$} & Count & 0 & 3 \\
\hline & & Percentage & $0 \%$ & $6.9 \%$ \\
\hline & \multirow[t]{2}{*}{$>50$} & Count & 0 & 3 \\
\hline & & Percentage & $0 \%$ & $6.9 \%$ \\
\hline \multirow{2}{*}{\multicolumn{2}{|c|}{ Total }} & Count & 3 & 8 \\
\hline & & Percentage & $6.9 \%$ & $18.4 \%$ \\
\hline
\end{tabular}

Chi-square statistic is 6.629. The p-value is 0.577

\begin{tabular}{|c|c|c|c|c|}
\hline \multicolumn{5}{|c|}{ Crosstab } \\
\hline & & & $\begin{array}{l}\text { INTRAMU } \\
\text { RAL LEAK }\end{array}$ & $\begin{array}{l}\text { EXTRAMUR } \\
\text { AL LEAK }\end{array}$ \\
\hline \multirow{10}{*}{$\begin{array}{l}\text { AGE } \\
\text { GROU } \\
P\end{array}$} & \multirow[t]{2}{*}{$<20$} & Count & 2 & 0 \\
\hline & & Percentage & $4.6 \%$ & $0 \%$ \\
\hline & \multirow[t]{2}{*}{$21-30$} & Count & 1 & 0 \\
\hline & & Percentage & $2.3 \%$ & $0 \%$ \\
\hline & \multirow[t]{2}{*}{$31-40$} & Count & 0 & 0 \\
\hline & & Percentage & $0 \%$ & $0 \%$ \\
\hline & \multirow[t]{2}{*}{$41-50$} & Count & 1 & 0 \\
\hline & & Percentage & $2.3 \%$ & $0 \%$ \\
\hline & \multirow[t]{2}{*}{$>50$} & Count & 1 & 1 \\
\hline & & Percentage & $2.3 \%$ & $2.3 \%$ \\
\hline \multirow{2}{*}{\multicolumn{2}{|c|}{ Total }} & Count & 5 & 1 \\
\hline & & Percentage & $11.6 \%$ & $2.3 \%$ \\
\hline
\end{tabular}

Chi-square statistic is 6.453 . The p-value is 0.597 
Per Oral Endoscopic Myotomy (POEM) is a novel endoscopic method for the treatment of achalasia cardia showing good results in terms of reduced recurrence and decreased duration of hospital stay. Present reports from various meta-analytic studies show short term promising results with minimal adverse events.

More than $2 / 3$ rd of the study population had pleural effusion. Of the 30 patients $(69.8 \%)$ who had pleural effusion, 20 patients $(46.5 \%)$ had bilaterally. Hence right sided effusion was more common with 27 $(62.8 \%)$ cases in total, as compared to 14 cases $(32.6 \%)$ with left sided effusion. Pleural effusion was the most common complication in our study $(69.8 \%)$. None of the 30 patients with pleural effusion needed aspiration or drainage. However one patient with extraluminal contrast leak eventually developed left empyema, for which intercostal drainage tube was kept

In the study by Ming-Yan Cai et al.[10] pleural effusion was the most commonly detected CT finding (66.7\%), similar to our study, of which only $1 \%(2 / 200)+$ of patients with pleural effusion needed aspiration because of clinical symptoms. Also in the study by Williams et al [11] pleural effusion was the most common complication (66\%).

Small pneumothorax was noted in 1 patient $(2.3 \%)$ in our study. The patient had no respiratory distress, and did not require any case specific management for it.

In the study by Ming-Yan Cai et al [10] the incidence of pneumothorax was higher $(16.7 \%)$. In that study, pneumothorax were detected in 50 patients $(16.7 \%)$, with 17 patients having pneumothorax volume $>30 \%$ requiring drainage (large pneumothorax). All of these patients had dyspnea. 32 patients had small $(<30 \%)$ pneumothorax, and they were asymptomatic. One patient with borderline pneumothorax (30\%) reported slight shortness of breath, who improved with oxygen, and no intervention was required. All cases of pneumothorax requiring drainage were observed only in the initial periods of the study when room air was used instead of $\mathrm{CO} 2$ insufflation, and did not occur after that. Similarly, the rates of small pneumothorax also decreased from $16.7 \%$ to $2.1 \%$ after the introduction of $\mathrm{CO} 2$ insufflation. This later rate of pneumothorax incidence was very similar to that of our study. In our study the procedure was routinely performed using $\mathrm{CO} 2$ insuffulator.

Similar to the above study, in the study by Williams et al [11] pneumothorax was reported in $17 \%$ cases, however the usage of $\mathrm{CO} 2$ insuffulator has not been commented.

One patient had 2 mucosal defects in the lower oesophagus along the lower aspect of the clip,

with extra luminal contrast leak, causing mediastinal collection and empyema. Empyema was managed with ICD tube. Follow up CT scan showed radiological improvement with reduction in the mediastinal collection and near complete resolution of the empyema. Minimal intramural contrast leak with no extraluminal leak was present in 5 patients $(11.6 \%)$, none of them had mediastinal collection or associated complications. They were managed with second clipping.

In the study by Patel et al [12] mediastinal leak with clinical significance was extremely rare, being reported in $0.3 \%$ cases. Of the 43 patients evaluated including 20 females and 23 males, pneumomediastinum were found in 11 patients $(25.5 \%)$, pneumoperitoneum in 24 patients $(60.5 \%)$ and subcutaneous emphysema in 12 patients $(28 \%)$. None of them required any intervention.

Similar results were reported in the study by Ming-Yan Cai et al [10] pneumomediastinum was present in $48.3 \%$ and pneumoperitoneum in $37.7 \%$ patients, but they did not require any intervention. Eighty-six patients $(28.7 \%)$ had subcutaneous emphysema, which resolved spontaneously.

Pneumonitis was seen in 3 cases $(6.9 \%)$. One case had bilateral lower lobe consolidation with nil significant adverse respiratory history preoperatively, suggesting the possibility of aspiration. The patient however had an uneventful postoperative course obviating the necessity of any further management. The remaining 2 patients with pneumonitis did not have clinical manifestation mandating specific management. Basal atelectasis was seen in 8 cases (18.4\%) and they did not cause any serious clinical manifestation. They did not warrant specific management and were clinically insignificant.

In the study by Ming-Yan Cai et al [10] pneumonitis was detected in $52.7 \%$ of patients, 69 unilateral and 89 bilateral. All of them were mild and did not cause serious clinical manifestation and no specific management was required.

In the study by Williams et al [11] pneumonitis and focal atelectasis were present in $52 \%$ and $21 \%$ of the cases respectively, and none caused any significant clinical manifestation.

One other expected complication is delayed bleeding, which has been reported in $0.7 \%$ of the cases in a large case study by Rawlings et al [13] which involved 428 patients. In our study we did not come across any case of bleeding or hematoma. Hematemesis with or without chest pain requires an emergent endoscopy and removal of the clips or sutures from the mucosal entry so that the submucosal tunnel and muscle can be assessed. In the aforementioned series, the bleeding point was identified in $2 / 3$ cases and in the third patient there was no focus found and the patient was effectively treated with a SengstakenBlackmore tube. It is important to note that hematoma in the tunnel can result in pressure necrosis of the mucosal flap with potentially disastrous consequences. The safety of the Sengstaken-Blackmore tube in this setting is also debated as it can potentially result in pressure necrosis of the already devascularized mucosa.

\section{CONCLUSION}

Per oral endoscopic myotomy (POEM) procedure off late has become the more preferred management of achalasia cardia. Hence the radiologists must be aware of the postoperative complications which are expected of the procedure and their clinical implications. Also more importantly the rare and more adverse complication like perforation which causes high morbidity and mortality has to be looked for, as their early detection may have significant impact on the prognosis.

\section{REFERENCES}

Pohl D, Tutuian R. Achalasia: an overview of diagnosis and treatment. J Gastrointes Liver Dis 2007;16:297-303

2. Boeckxstaens GE, Annese V, des Varannes SB, et al. Pneumatic dilation versus laparoscopic Heller's myotomy for idiopathic achalasia. N Engl J Med 2011;364:180716.

3. Costamagna G, Marchese M, Familiari P, et al. Peroral endoscopic myotomy (POEM) for oesophageal achalasia: preliminary results in humans. Dig Liver Dis 2012;44:82732

4. von Renteln D, Inoue H, Minami H, et al. Peroral endoscopic myotomy for the treatment of achalasia: a prospective single center study. Am J Gastroenterol 2012;107:411-7.

Inoue $\mathrm{H}$, Minami H, Kobayashi Y, et al. Peroral endoscopic myotomy (POEM) for esophageal achalasia. Endoscopy 2010;42:265-71

6. Swanstrom LL, Rieder E, Dunst CM. A stepwise approach and early clinical experience in peroral endoscopic myotomy for the treatment of achalasia and esophageal motility disorders. J Am Coll Surg 2011;213:751-6.

7. Minami H, Isomoto H, Yamaguchi N, et al. Peroralendoscopicmyotomy (POEM) for diffuse esophageal spasm.Endoscopy2014;46(supp11)UCTN:E79-81

8. Röhrich, S., Schlegl, T., Bardach, C. et al. Deep learning detection and quantification of pneumothorax in heterogeneous routine chest computed tomography. Eur Radiol Exp 4 , 26(2020). https://doi.org/10.1186/s41747-020-00152-7

9. Moy, M. P., Levsky, J. M., Berko, N. S., Godelman, A., Jain, V. R., \& Haramati, L. B. (2013). ANew, Simple Method for Estimating Pleural Effusion Size on CT Scans. Chest, 143(4), 1054-1059

10. Ming-Yan Cai, Ping-Hong Zhou, Li-Qing Yao, Bo-Qun Zhu, Liang Liang, Quan-Lin Li Chest CT in the management of post-POEM achalasia; Gastrointest Endosc 2014;80:1046-55.

11. Brian Williams, Jonathan Kass, Rishi Maheshwary, Krishna Gurram, Matthew Hartman. POEM Procedure: What the radiologist needs to know for this new surgical intervention for achalasia; Current Problems in Diagnostic Radiology (2016)

12. Patel K, Abbassi-GhadiN, MarkarS, etal. Peroral endoscopic myotomy for the treatmen of esophageal achalasia: Systematic review and pooled analysis. Dis Esophagus 2015 of esophageal achalasia: Systematic

13. Rawlings A, Soper NJ, Oelschlager B, Swanstrom L, Matthews BD, Pellegrini C, et al. Laparoscopic Dor versus Toupet fundoplication following Heller myotomy for achalasia: results of a multicenter, prospective, randomized-controlled trial. Surg Endosc 2012; 26: 18-26 [PMID: 21789646 DOI: 10.1007/s00464-011-1822-y] 